\title{
TAM family receptors in conjunction with MAPK signalling are involved in acquired resistance to PI3Ka inhibition in head and neck squamous cell carcinoma
}

Kara M. Ruicci ${ }^{1,2}$, Jalna Meens ${ }^{3}$, Paul Plantinga ${ }^{2}$, William Stecho ${ }^{2}$, Nicole Pinto ${ }^{1}$, John Yoo ${ }^{1,4}$, Kevin Fung ${ }^{1,4}$, Danielle MacNeil ${ }^{1,4}$, Joe S. Mymryk ${ }^{1,4,5}$, John W. Barrett ${ }^{1}$, Christopher J. Howlett ${ }^{2}$, Paul C. Boutros ${ }^{6,7,8+}$, Laurie Ailles $s^{3,9+}$ and Anthony C. Nichols $s^{1,2,4^{*}+}$

\begin{abstract}
Background: Aberrant activation of the phosphatidylinositol 3-kinase (PI3K) pathway is common in many malignancies, including head and neck squamous cell carcinoma (HNSCC). Despite pre-clinical and clinical studies, outcomes from targeting the PI3K pathway have been underwhelming and the development of drug resistance poses a significant barrier to patient treatment. In the present study, we examined mechanisms of acquired resistance to the PI3Ka inhibitor alpelisib (formerly BYL719) in HNSCC cell lines and patient-derived xenografts (PDXs).

Methods: Five unique PDX mouse models and three HNSCC cell lines were used. All cell lines and xenografts underwent genomic characterization prior to study. Serial drug treatment was conducted in vitro and in vivo to develop multiple, clinically-significant models of resistance to alpelisib. We then used reverse phase protein arrays (RPPAs) to profile the expression of proteins in parental and drug-resistant models. Top hits were validated by immunoblotting and immunohistochemistry. Flow cytometric analysis and RNA interference studies were then used to interrogate the molecular mechanisms underlying acquired drug resistance.

Results: Prolonged treatment with alpelisib led to upregulation of TAM family receptor tyrosine kinases TYRO3 and AXL. Importantly, a significant shift in expression of both TYRO3 and AXL to the cell surface was detected in drugresistant cells. Targeted knockdown of TYRO3 and AXL effectively re-sensitized resistant cells to PI3Ka inhibition. In vivo, resistance to alpelisib emerged following 20-35 days of treatment in all five PDX models. Elevated TYRO3 expression was detected in drug-resistant PDX tissues. Downstream of TYRO3 and AXL, we identified activation of intracellular MAPK signalling. Inhibition of MAPK signalling also re-sensitized drug-resistant cells to alpelisib.

(Continued on next page)
\end{abstract}

\footnotetext{
* Correspondence: Anthony.Nichols@lhsc.on.ca

${ }^{+}$Paul C. Boutros, Laurie Ailles and Anthony C. Nichols are co-authors.

'Department of Otolaryngology - Head and Neck Surgery, Schulich School of

Medicine \& Dentistry, Western University, Room B3-431A, 800 Commissioners

Road East, London, ON N6A 5W9, Canada

${ }^{2}$ Department of Pathology \& Laboratory Medicine, Schulich School of

Medicine \& Dentistry, Western University, London, ON, Canada

Full list of author information is available at the end of the article
}

(C) The Author(s). 2020 Open Access This article is licensed under a Creative Commons Attribution 4.0 International License, which permits use, sharing, adaptation, distribution and reproduction in any medium or format, as long as you give appropriate credit to the original author(s) and the source, provide a link to the Creative Commons licence, and indicate if changes were made. The images or other third party material in this article are included in the article's Creative Commons licence, unless indicated otherwise in a credit line to the material. If material is not included in the article's Creative Commons licence and your intended use is not permitted by statutory regulation or exceeds the permitted use, you will need to obtain permission directly from the copyright holder. To view a copy of this licence, visit http://creativecommons.org/licenses/by/4.0/ The Creative Commons Public Domain Dedication waiver (http://creativecommons.org/publicdomain/zero/1.0/) applies to the data made available in this article, unless otherwise stated in a credit line to the data. 


\begin{abstract}
(Continued from previous page)
Conclusions: We have identified TYRO3 and AXL receptors to be key mediators of resistance to alpelisib, both in vitro and in vivo. Our findings suggest that pan-TAM inhibition is a promising avenue for combinatorial or second-line therapy alongside PI3Ka inhibition. These findings advance our understanding of the role TAM receptors play in modulating the response of HNSCC to PI3Ka inhibition and suggest a means to prevent, or at least delay, resistance to PI3Ka inhibition in order to improve outcomes for HNSCC patients.
\end{abstract}

Keywords: Alpelisib, BYL719, PI3-kinase, PI3K, Head and neck cancer, HNSCC, AXL, TYRO3

\section{Background}

Head and neck squamous cell carcinoma (HNSCC), which arises in the mucosa of the oral cavity, pharynx and larynx, is the 6th most common cancer worldwide [1]. Despite advances in available treatments (surgery, radiation, chemotherapy), survival rates at 5 years remain poor. Further, even patients cured by conventional treatment are frequently left with impairments in their abilities to speak, swallow and breathe, as well as facial disfigurements [2]. The development and clinical implementation of targeted therapeutics is needed to improve the survival outcomes and relieve the toxic burden associated with current HNSCC treatments.

The phosphatidylinositol 3-kinase (PI3K)/Akt/mTOR pathway is a major growth signalling pathway that regulates a variety of cellular processes, including protein and lipid synthesis, proliferation and cell survival [3]. The PI3K pathway is the most frequently dysregulated pathway in HNSCC, across both HPV-positive and HPV-negative HNSCC tumors [4-6]. Dysregulation of PI3K signalling-stemming from activating mutations or amplifications of PIK3CA-leads to constitutive activation of the pathway, which can promote tumor development and progression [5-7]. Given the prevalence of PI3K pathway alterations in HNSCC and the role this network plays in tumorigenesis, inhibiting this pathway is a logical therapeutic approach [7].

Various inhibitors that target one or more of the PI3K isoforms have entered clinical trials [7]. In fact, the $\alpha$ isoform specific PI3K inhibitor alpelisib (Piqray, ${ }^{\circ}$ Novartis) was recently approved by the US Food and Drug Administration (FDA) for treatment of PIK3CA-mutated, advanced or metastatic breast cancer. To date however, PI3K inhibitors as single agents have generally displayed limited efficacy. These drugs have typically led to cytostasis, rarely inducing tumor cell death or shrinkage $[7,8]$. Moreover, in patients who initially respond to targeted PI3K inhibition, acquired resistance over time has been cited [9].

Acquired resistance to PI3K inhibition is an area of active research [9-14]. In ovarian cancer, elevated expression of receptor tyrosine kinases (RTKs), including HER2 and EGFR, as well as increased activation of Src, c-Jun and STAT3 have been implicated in mediating resistance to PI3K inhibition by NVP-BEZ235 [11]. In breast cancer, genetic alterations in PTEN resulting in loss of expression have been identified in a patient who initially achieved a clinical response to PI3K inhibition before progressing rapidly [9]. Only a limited number of studies to date have examined acquired resistance to PI3K inhibition in HNSCC. Of these, resistance to the pan-PI3K inhibitor BKM120 has been shown to involve positive feedback activation of IL-6/ERK signalling, while resistance to the $\alpha$-isoform specific PI3K inhibitor alpelisib has been associated with growth signalling through the PLC $\gamma$-PKC network, downstream of the RTK AXL $[12,15]$. It is evident that a number of distinct mechanisms and mediators of resistance to PI3K inhibition exist and may be context-specific according to the drug used and/or cancer type.

As mentioned, alpelisib (formerly BYL719) is an $\alpha$ isoform specific PI3K inhibitor. It has been shown to exhibit "on-target" PI3K inhibition and anti-cancer efficacy, collectively leading to its recent FDA approval for breast cancer treatment $[7,8,16]$. Alpelisib targets the $p 110 \alpha$ catalytic subunit of the Class IA PI3K enzyme encoded by PIK3CA [17]. Due to the prevalence of genomic aberrations in PIK3CA observed in HNSCC, including gain of function mutations and amplifications, alpelisib is a particularly relevant drug. Further, by targeting only the $\alpha$-isoform, alpelisib has shown to have better tolerability than other, broader-acting PI3K inhibitors, with generally manageable side effects (e.g. hyperglycemia) [8]. To date, there have been few investigations of how resistance to PI3K inhibition by alpelisib is acquired in the context of HNSCC [12]. Further, most studies have been limited to in vitro investigations and have not made use of patient-derived xenograft (PDX) models to explore resistance and/or validate their findings [12, 18].

To capitalize on the promise of PI3K inhibitors in HNSCC, it is essential to understand resistance mechanisms that may be acquired over time; this will enable the design of drug combinations that will be both tolerable and durable [19]. In the present study, we explored acquired resistance to alpelisib using both HNSCC cell lines and HNSCC PDXs. We observed elevated expression of the AXL RTK, in line with other studies, as well as elevation of its family member TYRO3 in alpelisib- 
resistant HNSCC models [12]. Further, we interrogated MAPK pathway activation downstream of AXL and TYRO3 as a critical network for circumventing PI3K inhibition. Collectively our findings emphasize TYRO3 and AXL as key mediators of acquired resistance to PI3K inhibition in HNSCC, through the MAPK pathway. Pan-TAM inhibition may be a promising second-line therapy for HNSCC patients receiving PI3K-targeted agents.

\section{Materials \& methods}

\section{Cell lines and chemical compounds}

Cell lines were obtained from the sources listed (Additional Table 1). We previously used short tandem repeat profiling (The Center for Applied Genetics; Toronto) to confirm cell line identities [20]. 93-VU-147T cells were cultured in DMEM/F12, with $10 \%$ fetal bovine serum (FBS; GIBCO), penicillin (100 IU/mL; Invitrogen) and streptomycin $(100 \mu \mathrm{g} / \mathrm{mL}$; Invitrogen). Cal33 cells were cultured in DMEM, with 10\% heat-inactivated FBS, $1 \mathrm{x}$ non-essential amino acids (Wisent), penicillin (100 IU/ $\mathrm{mL})$ and streptomycin $(100 \mu \mathrm{g} / \mathrm{mL})$. Resistant cell lines were obtained after chronic exposure to increasing concentrations of alpelisib for 3-4 months [22]. All cells were maintained in a $37^{\circ} \mathrm{C}$ humidified atmosphere at $5 \%$ $\mathrm{CO}_{2}$. The inhibitors alpelisib and BI-D1870 were purchased from Selleckchem. Compounds were dissolved in DMSO for in vitro experiments.

\section{Establishment of patient derived xenografts}

Mice were handled in accordance with the AUP 1542 approved by the University Health Network Animal Care Committee and in accordance with the CCAC regulations. Xenografts were established and handled as described previously [21]. Details are provided as Supplemental Methods \& Materials.

Once tumor volumes reached $80-120 \mathrm{~mm}^{3}$ mice were randomized to either daily ( $5 \mathrm{x} /$ week) alpelisib (Novartis; $50 \mathrm{mg} / \mathrm{kg}$ ) by oral gavage or a vehicle control (corn oil) $[12,21]$. Individual tumor volumes were calculated using the formula: [length $\mathrm{x}(\text { width })^{2}$ ] $\times 0.52$. Where possible, STR profiling was used to confirm matching identities of primary tumors, xenograft tumors, patient blood and PDX-derived cell lines where available (Additional Table 2). Tumors were classified as HPV-positive using immunohistochemistry (IHC) for p16.

\section{Dose response curves}

Cells were seeded in 96-well plates at 2400 cells/well and cultured overnight. Drugs were then added over 10point ranges $(0-40 \mu \mathrm{M})$. Viability was determined $72 \mathrm{~h}$ later using the PrestoBlue ${ }^{\circ}$ Reagent (Thermo Fisher Scientific) on a Synergy ${ }^{\text {mi }}$ H4 Hybrid Reader (BioTek) with $560 \mathrm{~nm}$ excitation and $590 \mathrm{~nm}$ emission wavelengths.
For each dose, viability values were normalized to nodrug controls and average viability for each dose was calculated. To determine the half-maximal inhibitory concentration $\left(\mathrm{IC}_{50}\right)$ values, normalized relative fluorescence values of drug-treated replicates were calculated as a percentage of the mean RFU of the control replicates and then drug doses were transformed to a logarithmic scale. $\mathrm{IC}_{50}$ values were subsequently calculated by nonlinear regression. Values are plotted as mean \pm standard deviation (SD) using Prism ${ }^{\circ} 7$ GraphPad Software.

\section{Clonogenic survival assay}

Parental and resistant cell lines were counted and seeded at 500 cells per well into 24-well dishes. Cells were allowed to adhere for $48 \mathrm{~h}$ and then were treated with media containing $5 \mu \mathrm{M}$ alpelisib. For the next 7-14 days, cells were monitored and media replaced every 3 days until visible colonies were formed. Colonies were rinsed with $1 \mathrm{x}$ PBS, fixed with cold $100 \%$ methanol $(\mathrm{MeOH})$ and stained with $0.5 \%$ crystal violet in $25 \% \mathrm{MeOH} / 1 \mathrm{x}$ PBS. The colonies were then gently washed with water and air-dried. Visible colonies were counted.

\section{Reverse phase protein arrays}

Cells were prepared for reverse phase protein arrays (RPPAs) as follows: $10 \mathrm{~cm}$ plates were washed twice with cold 1x PBS. Cold lysis buffer (containing: 1\% Triton X100, $50 \mathrm{mM}$ HEPES pH 7.4, $150 \mathrm{mM} \mathrm{NaCl}, 1.5 \mathrm{mM}$ $\mathrm{MgCl} 2,1 \mathrm{mM}$ EGTA, $100 \mathrm{mM} \mathrm{NaF}, 10 \mathrm{mM}$ Na pyrophosphate, $1 \mathrm{mM} \mathrm{Na} 3 \mathrm{VO} 4,10 \%$ glycerol and 1\% freshlyadded protease and phosphatase inhibitors) was added to the plates which were then incubated $20 \mathrm{mins}$ on ice with occasional shaking. Lysed cells were centrifuged at $14000 \mathrm{rpm}$ for $10 \mathrm{mins}$ at $4{ }^{\circ} \mathrm{C}$. Protein concentration determined by Bradford Assay. Lysates were combined with sample buffer (40\% glycerol, 8\% SDS, 0.25 M Tris$\mathrm{HCl} \mathrm{pH} 6.8$ and $1 / 10$ volume $\beta$-mercaptoethanol -added just before use) at 3 parts lysate: 1 part sample buffer. Samples were boiled for 5 mins and stored at $-80^{\circ} \mathrm{C}$.

Samples were submitted to MD Anderson's Functional Proteomics RPPA Core Facility. Briefly, lysates were serially diluted and arrayed onto nitrocellulose-coated glass slides. Samples were probed with 307 antibodies and visualized by DAB colorimetric reaction. Slides were then scanned and spot densities quantified by Array-Pro Analyzer. All data points were normalized for protein loading and transformed to a linear value. Resistant replicates were then normalized to the mean of their respective parental replicates. Values were then log2transformed and we restricted our analysis to the top $50 \%$ of differentially-expressed proteins for each cell line. Unsupervised hierarchical clustering was performed using the average agglomeration method and Euclidean 


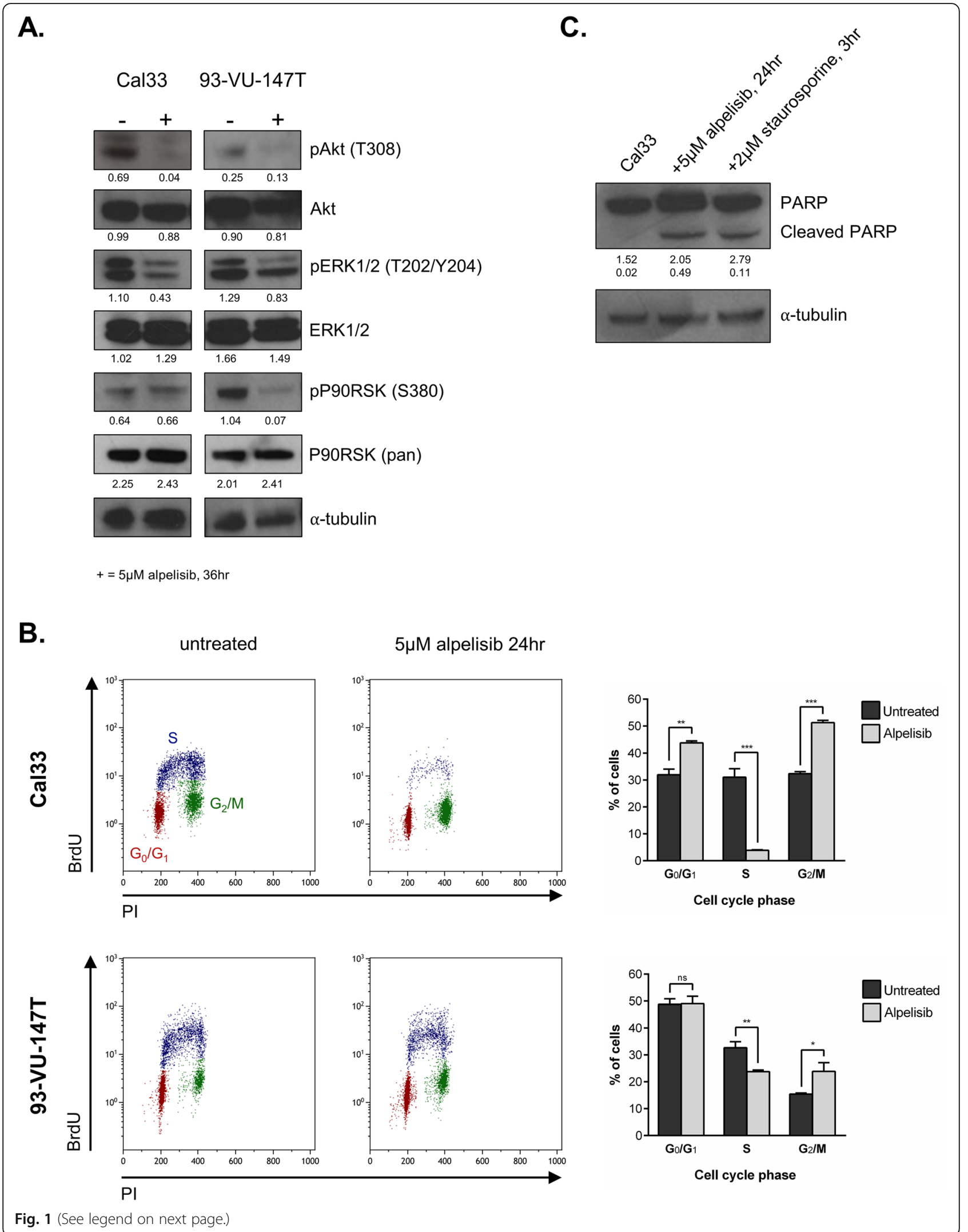


(See figure on previous page.)

Fig. 1 Alpelisib inhibits growth and PI3K signalling in HNSCC cells. a Immunoblot of PI3K and MAPK pathway members Akt, ERK1/2 and P90RSK following treatment with $5 \mu \mathrm{M}$ alpelisib for $36 \mathrm{~h}$. Densitometric quantification of each protein relative to a-tubulin is shown below each band. $\mathbf{b}$ Flow cytometric analysis of Cal33 and 93-VU-147T cells treated with alpelisib $(5 \mu \mathrm{M})$ for $24 \mathrm{~h}$ (3 replicates per line) before BrdU incorporation and labeling with propidium iodide. Approximately 10,000 events were counted per test (5000 events are shown in each figure). Proportion of cells in each cell cycle phase is shown, \pm standard deviation. * represents $p<0.05,{ }^{* *}$ represents $p<0.01,{ }^{* * *}$ represents $p<0.001$, ns $=$ not significant, unpaired Student's $t$-test. c Immunoblot for PARP cleavage in Cal33 cells treated with alpelisib $(5 \mu \mathrm{M})$ for $24 \mathrm{~h}$, or staurosporine $(2 \mu \mathrm{M})$ for $3 \mathrm{~h}$, as a positive control. Densitometric quantification of each protein relative to a-tubulin is shown below each band

distance measurements. Clustering was performed in $\mathrm{R}$ using the ComplexHeatmap package (version 2.1.1).

\section{Immunoblotting and densitometric analysis}

Cell lysates were prepared for immunoblotting as described previously [23]. A list of primary antibodies used is provided in Additional Table 3. Membranes were visualized following exposure to enhanced chemiluminescence reagent (Luminata ${ }^{\mathrm{TM}}$ Crescendo or Luminata ${ }^{\mathrm{TM}}$ Forte, Western HRP Substrate; Millipore) on a Bio-Rad ChemiDoc ${ }^{\mathrm{Tm}} \mathrm{MP}$ Imaging System.

Image was used to select and determine the background-subtracted density of the bands in all immunoblots. Values were then normalized to their corresponding $\alpha$-tubulin band. All values are presented below the associated band.

\section{Tissue microarray (TMA) and immunohistochemistry}

TMAs were constructed for two of the xenograft models. In brief, the FFPE block for each tumor was sectioned and stained with hematoxylin \& eosin ( $\mathrm{H} \& \mathrm{E})$ to confirm the presence of human tumor. Guided by these sections, a Manual Tissue Arrayer (MTA-1; Beecher Instruments Inc.) was used to punch out 3-4 cylindrical cores of $0.6 \mathrm{~mm}$ diameter from each sample. Cores were arrayed into recipient paraffin blocks. Eleven control tissues (tonsil, stomach, prostate, pancreas, lung, kidney, skin, thyroid, spleen, adipose, liver) were also included on each block. Cores were sealed into recipient blocks by heating at $40{ }^{\circ} \mathrm{C}$ for $\sim 40$ mins. Blocks were sectioned into $1.5 \mu \mathrm{M}$ sections and affixed to glass slides. Every ninth slide was stained with $\mathrm{H}$ \& $\mathrm{E}$ to provide a reference. Additional details are available in the MTA-1 Instruction Manual (www.beecherinstruments.com). IHC staining was completed in collaboration with the Department of Pathology \& Laboratory Medicine and the Molecular Pathology Core Facility (Western University). Tissues were examined using an Aperio ScanScope ${ }^{\bullet}$ slide scanner and staining quantification was performed using the Fiji plugin for ImageJ.

\section{Flow cytometry for cell surface expression of RTKs}

Parental and resistant cells were collected by trypsinization, washed in 1x PBS and counted. Single-cell suspensions were incubated in a $5 \%$ BSA solution containing
anti-AXL or TYRO3, PE-conjugated antibodies at 1:50 ( $\mathrm{R} \& \mathrm{D}$ Biosystems) for 40mins in the dark at room temperature. Cells were passed through a cell strainer to collect single cells and were protected from light until they were quantified using a Beckman-Coulter Cytomics FC500 flow cytometer with at least 10,000 events counted per test. Histograms were used to compare intensity of staining between unstained, parental and resistant cell line samples. Median fluorescence intensity was calculated for each sample and $t$-tests were used to quantify differences.

\section{RNA interference}

Knockdown of AXL and TYRO3 was performed using specific pooled siRNAs purchased from Dharmacon (Cat No's. L-003104-00-0005 and L-003183-00-0005, respectively), as described previously [23]. Scrambled control siRNA (siCT) (Thermo Fisher Scientific; Cat No. 4390843) was also used. Knockdowns were confirmed by immunoblotting.

For drug testing, cells were seeded into 96-well dishes at 2400 cells/well. Alpelisib was added the next day at $5 \mu \mathrm{M}$ and cells were incubated for $72 \mathrm{~h}$. Cell viability was then determined indirectly using the PrestoBlue ${ }^{\oplus}$ Reagent (Thermo Fisher Scientific) on a Synergy ${ }^{\mathrm{TM}}$ H4 Hybrid Reader (BioTek) with $560 \mathrm{~nm}$ excitation and $590 \mathrm{~nm}$ emission wavelengths. For each condition, alpelisib-treated cells were compared with normalized untreated cells to determine the relative effect of RNAi-mediated knockdown.

\section{Generation of PDX-derived cell line}

Using cells dissociated from first-passage xenograft tumors, we attempted to establish cell lines from the patient tumors that were used to generate the PDX models (Additional Fig. 1a). Specifically, the generation of cell lines was attempted from tumor tissues that were never treated with alpelisib nor the vehicle agent. A cell line (called PDX-C Cell Line) was successfully established from one model, PDX-C (Additional Fig. 1b). STR profiling, immunoblotting and flow cytometry for cell surface expression of EpCAM (CD326) were all completed as described previously, validating the line as a human epithelial line from the same patient as the PDX-C tumor (Additional Fig. 1c, Additional Table 2). 


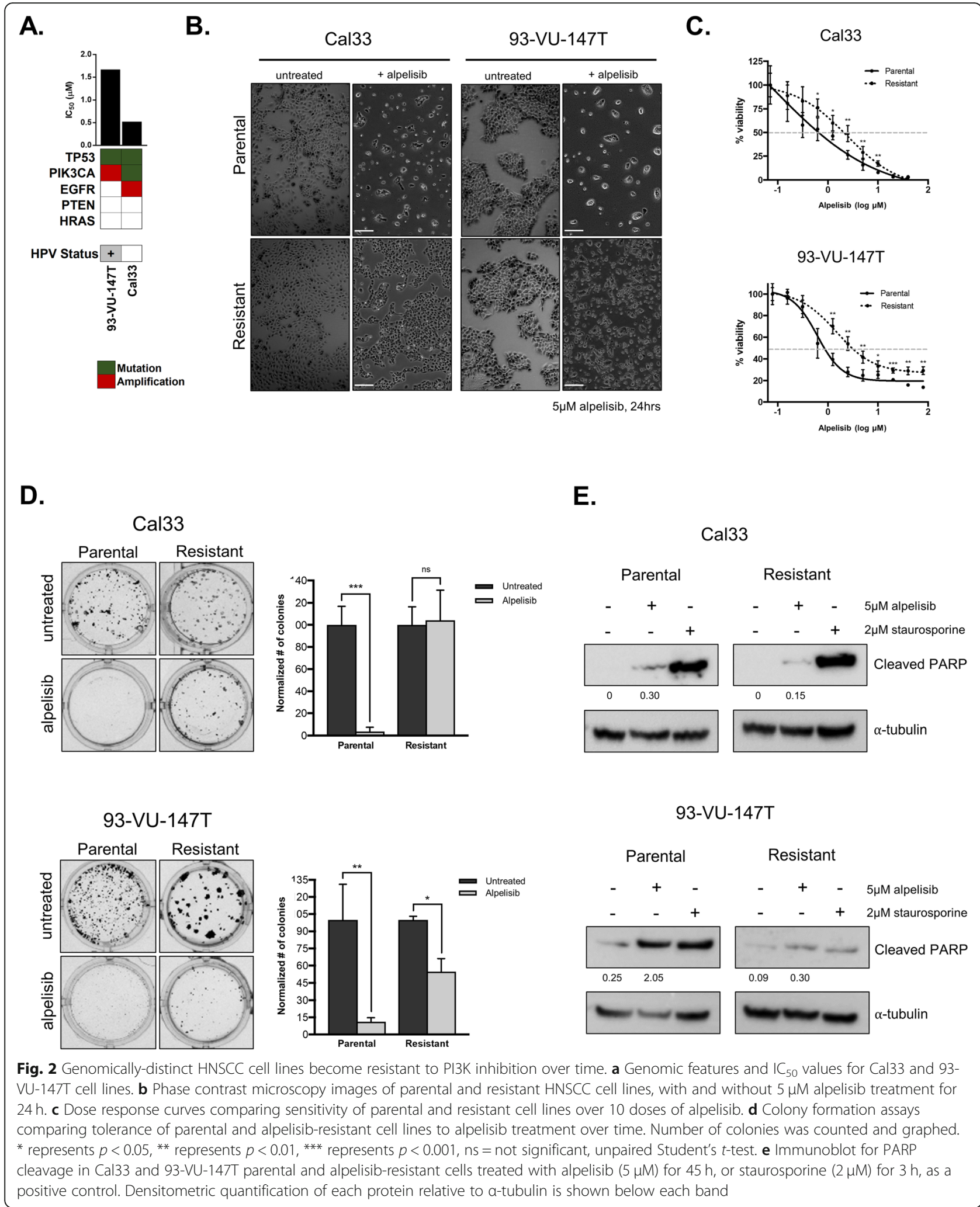




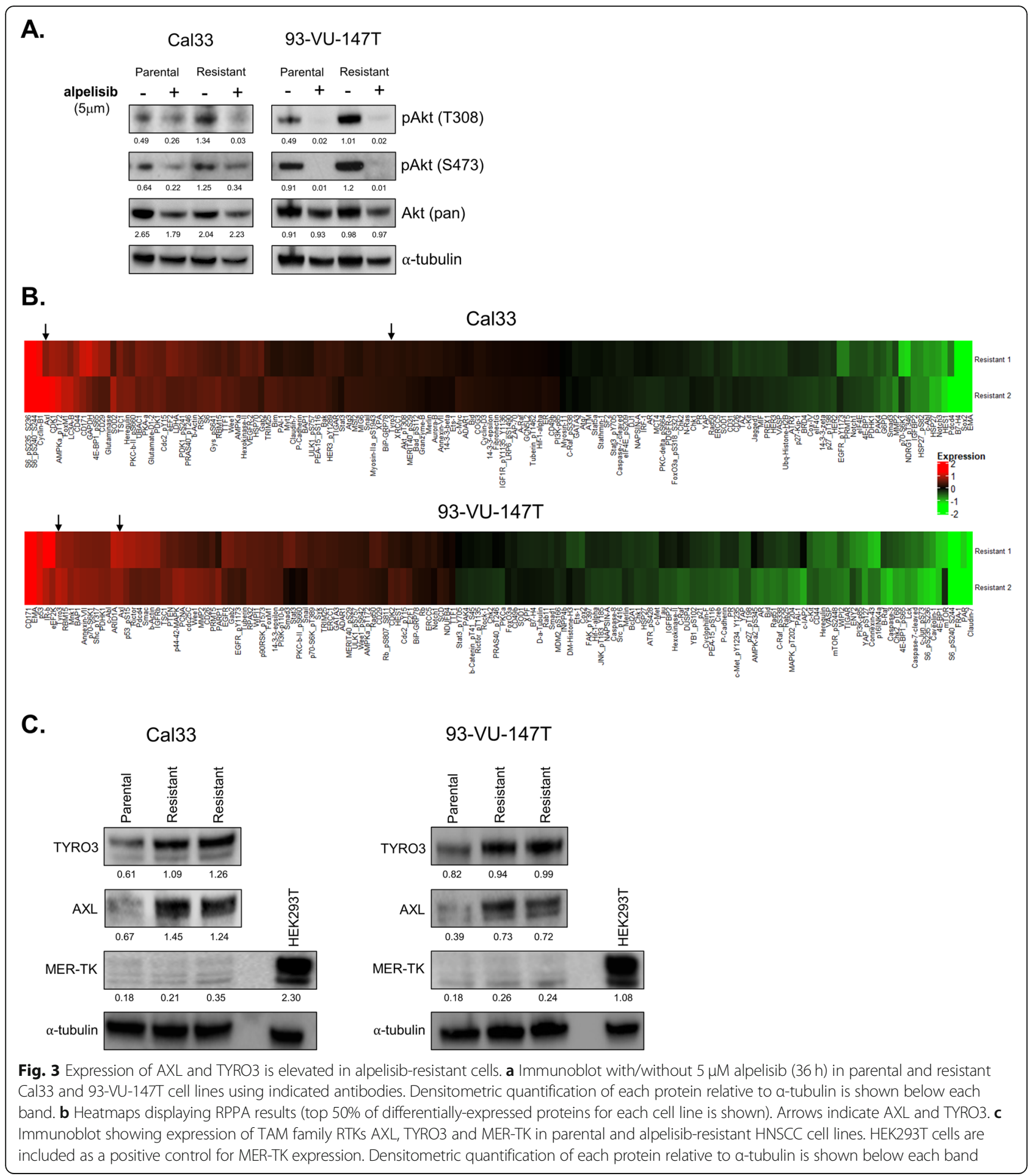

\section{Statistical analysis}

All analyses were performed with Prism ${ }^{\circ} 7$ GraphPad Software. Experimental groups were compared with controls using Student's unpaired, two-tailed $t$-tests. Multiple groups were compared across a single condition using one-way ANOVA. $P<0.05$ was used to define significant differences from the null hypothesis.

\section{Results}

Alpelisib inhibits growth and PI3K signalling in HNSCC cells

Prior to exploring resistance to PI3K inhibition, we first validated the efficacy of alpelisib in HNSCC cell lines. Alpelisib treatment reduced signalling through both the PI3K and MAPK pathways in Cal33 (PIK3CA mutant) 
A.
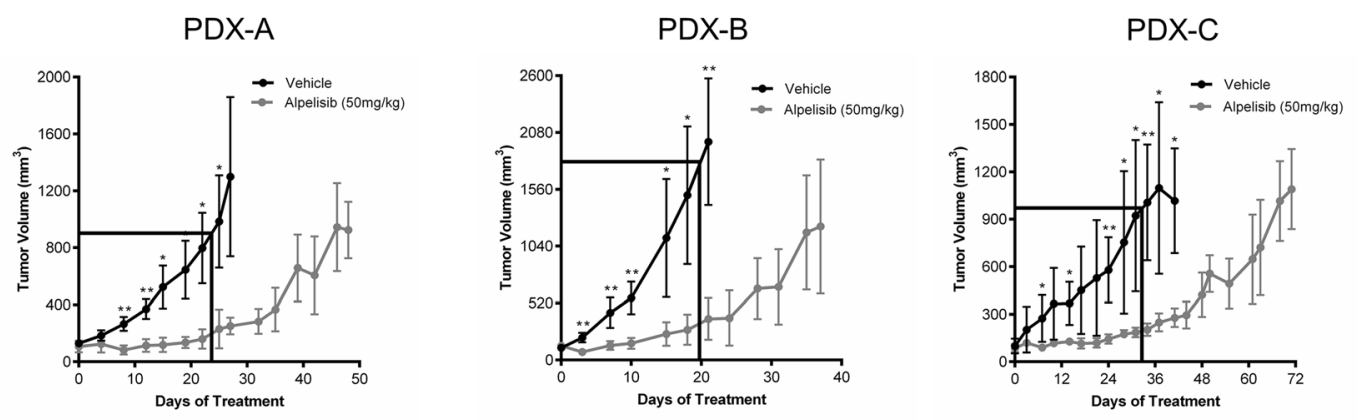

PDX-D

PDX-E
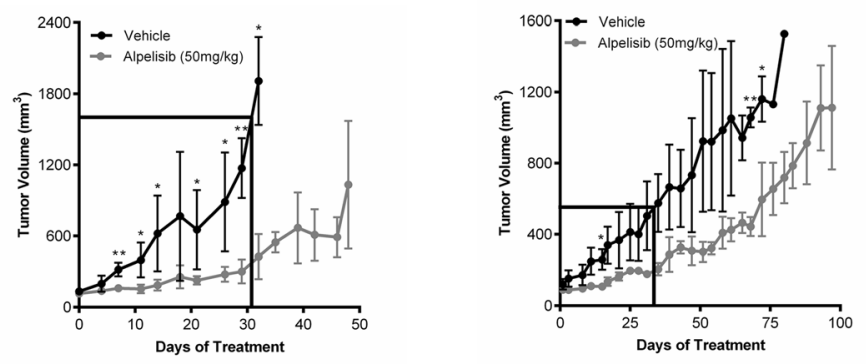

B.
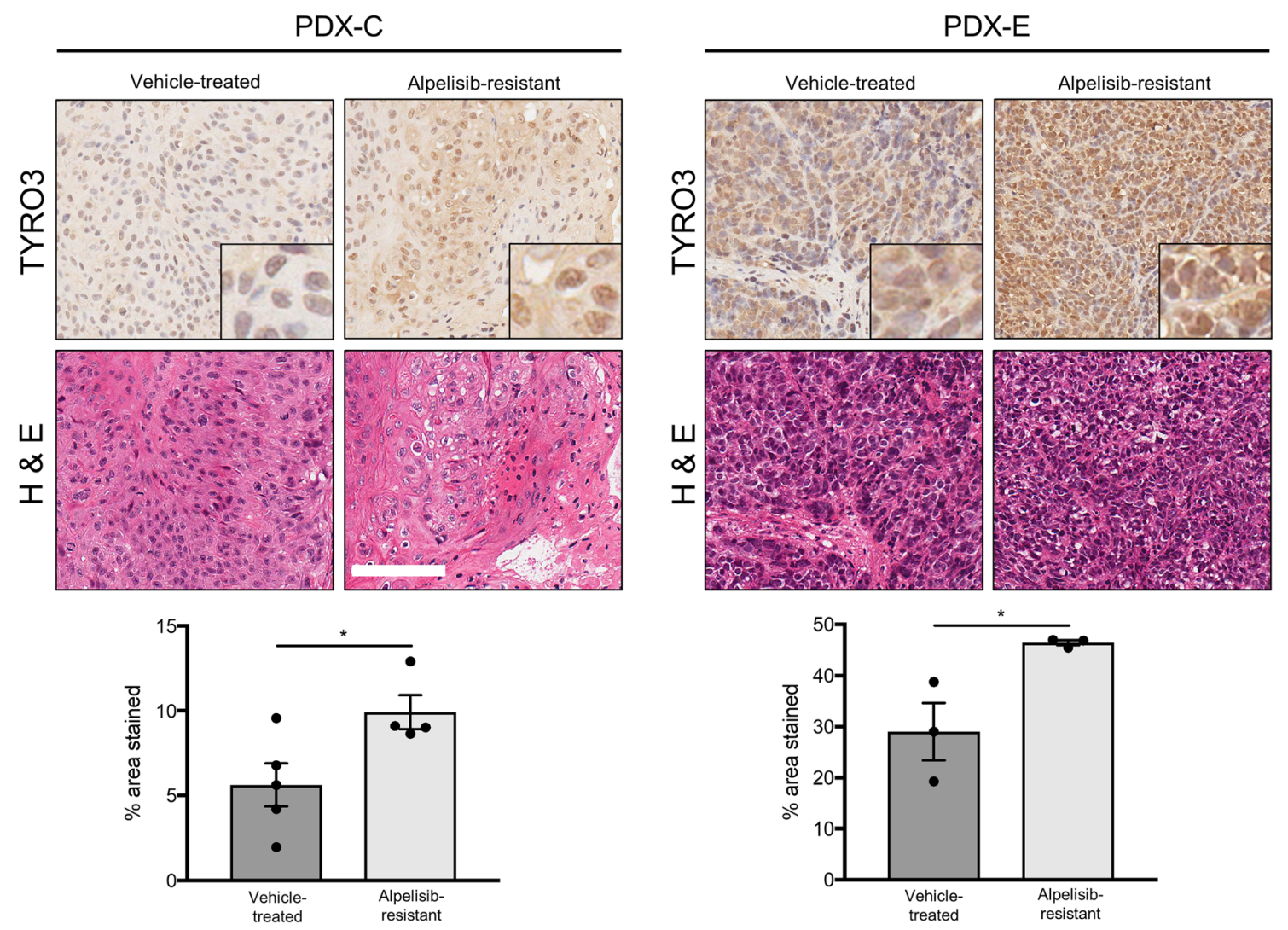

Fig. 4 (See legend on next page.) 
(See figure on previous page.)

Fig. 4 Genomically-distinct HNSCC PDX models develop resistance to alpelisib following prolonged treatment. a Growth curves for PDX models treated over time with alpelisib. 5 mice per arm received either alpelisib $\left(50 \mathrm{mg} / \mathrm{kg}\right.$ ) or a vehicle agent (corn oil). ${ }^{*}$ represents $p<0.05$, ** represents $p<0.01$, unpaired Student's t-test. Boxed out region highlights early treatment days where alpelisib-treated tumors showed static growth relative to the vehicle treatment. b Representative IHC sections showing TYRO3 staining in PDX-C and PDX-E models. Quantification was completed using Fiji software and is shown below. ${ }^{*}$ represents $p<0.05$, unpaired Student's $t$-test. Scale bars represent $100 \mu M$

cells and 93-VU-147T (PIK3CA amplified) cells (Fig. 1a), as indicated by reduced levels of phosphorylated (p)-Akt (Thr308), pERK1/2 (Thr202/Tyr204) and pP90RSK (Ser380) [21]. Based on previous studies, we hypothesized that the mechanism of action for alpelisib in HNSCC would involve cell cycle arrest [7]. Following 24 $\mathrm{h}$ of treatment with alpelisib, we observed a significant reduction in the proportion of proliferating (S-phase) cells (Fig. 1b) [24, 25]. To determine whether alpelisib was also able to induce cell death through apoptosis, we examined PARP cleavage (Fig. 1c). Following alpelisib treatment, cleaved PARP was readily detectable. Of note, we have also previously characterized the sensitivity of 28 HNSCC cell lines to PI3K inhibition and found both wildtype and PIK3CA-altered cell lines to be sensitive to PI3K inhibition [21].

\section{Genomically-distinct HNSCC cell lines develop resistance to alpelisib}

To identify pathways associated with acquired resistance to alpelisib, we exposed two genomically-distinct HNSC $\mathrm{C}$ cell lines (Fig. 2a) to increasing concentrations of alpelisib over a 3-4 month period (schematic shown in Additional Fig. 2), ultimately yielding cell lines significantly more resistant to alpelisib than their parental counterparts (Fig. 2b-c) [21]. To verify the durability of the resistant cell lines, parental and resistant cells were challenged to grow as single cell colonies in the presence of alpelisib. Whereas alpelisib treatment led to a significant reduction in the number of colonies formed by both parental cell lines, it was much less effective in resistant cell lines (Fig. 2d). Although the alpelisibresistant 93-VU-147T cells exhibited a modest reduction in colony formation following alpelisib treatment, the difference was much less than that of the parental line. Thus, cell lines treated for a prolonged period with alpelisib exhibit increased tolerance for this PI3K inhibitor. In addition, we examined the relative abundance of colony sizes (small, medium, large) in parental versus resistant cell lines as this reflects cell lines' proliferative status (Additional Fig. 3a-b). Finally, to compare the ability of alpelisib to induce cell death through apoptosis, we examined PARP cleavage following alpelisib treatment in parental and alpelisib-resistant cell lines (Fig. 2e). We found that following alpelisib treatment, cleaved PARP was readily detectable in parental cells, but was less abundant in alpelisib-resistant cells, suggesting that alpelisib treatment is less effective at inducing cell death via apoptosis in cells that have acquired resistance to alpelisib.

To determine whether alpelisib continued to block signalling through the PI3K pathway in drug-resistant cells, we used immunoblotting to examine Akt phosphorylation following alpelisib treatment in parental and resistant cell lines. In parental and drug-resistant cell lines alike, alpelisib treatment suppressed Akt Thr308 and Ser473 phosphorylation, indicating that resistance was acquired via a compensatory mechanism and not loss of direct inhibition of PI3K activity (Fig. 3a).

\section{Expression of AXL and TYRO3 is elevated in alpelisib- resistant cells}

To examine a broad array of signalling pathways that could mediate resistance to PI3K inhibition in HNSCC cells, we performed RPPAs on lysates from Cal33 and 93-VU-147T parental cells and resistant cell lines (Fig. 3b). In both resistant cell lines, RPPAs suggested that expression of the membrane-bound RTK AXL was elevated relative to parental cells. As mentioned, AXL has been previously shown to mediate resistance to various anti-cancer agents, including EGFR, HER2 and PI3Ktargeted therapies [12, 26-28]. AXL is part of a threemember RTK sub-family known as the 'TAM family' of receptors (TYRO3, AXL, MER-TK) [29-32]. Interestingly, expression of TYRO3 was also found to be elevated in both Cal33 and 93-VU-147T alpelisib-resistant cells. To our knowledge, TYRO3 has never been implicated in PI3K-inhibitor resistance, nor in HNSCC as an effector of therapy response. In general, much less is known about TYRO3, including the role it plays in cancer development and progression [31-34].

We confirmed elevated protein expression of AXL and TYRO3 in alpelisib-resistant Cal33 and 93-VU-147T cells, relative to parental cells by immunoblotting (Fig. 3c). We also examined expression of the third member of the TAM RTK family, MER-TK, which was not included in the RPPA. MER-TK was weakly detectable in both HNSC $C$ cell lines, in contrast to its high expression in HEK293T cells (long exposure blots shown in Additional Fig. 4a-b). As MER-TK was only weakly detected in both cell lines and no difference in expression was apparent between parental and drug-resistant cells, we did not examine it further. Based on our findings, we hypothesized that overexpression of TYRO3 and/or AXL receptors could play a role in mediating resistance to $\mathrm{PI} 3 \mathrm{~K} \alpha$ inhibition. 


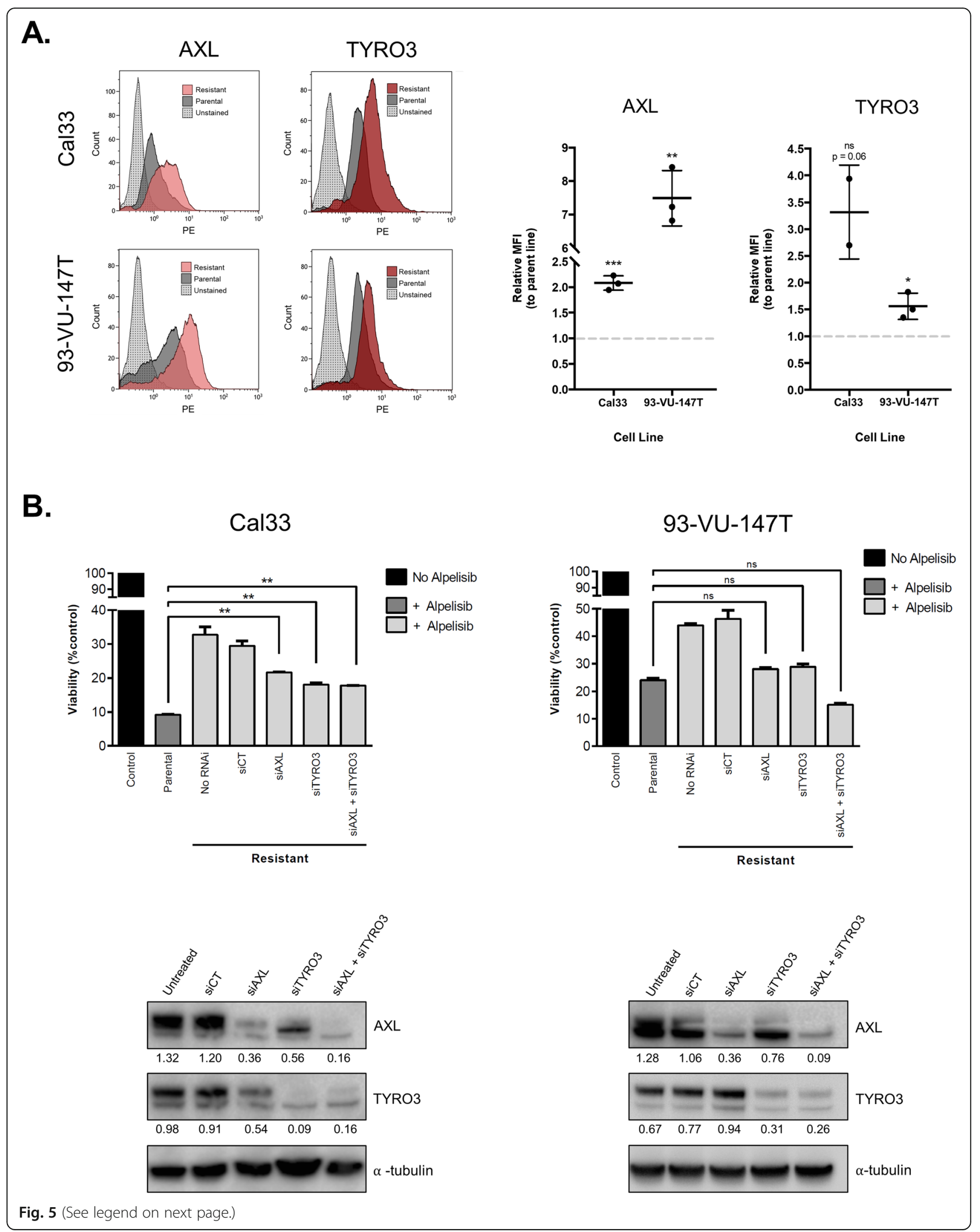


(See figure on previous page.)

Fig. 5 TYRO3 and AXL modulate sensitivity to alpelisib. a Flow cytometric analysis of AXL and TYRO3 in parental and resistant HNSCC cell lines. Median fluorescence intensity (MFI) was measured and graphed for three biological replicates. ${ }^{*}$ represents $p<0.05,{ }^{* *}$ represents $p<0.01, * * *$ represents $p<0.001,{ }^{* * *}$ represents $p<0.0001$, ns $=$ not significant, unpaired Student's $t$-test. b siRNA-mediated knockdown of $A X L$ (siAXL) and TYRO3 (siTYRO3) in Cal33 and 93-VU-147T cells. siCT = scrambled control siRNA, RNAi = RNA interference. ** represents $p<0.01$, ns $=$ not significant. One-way ANOVA. Immunoblot of AXL and TYRO3 expression following siRNA-mediated knockdowns is shown below, siCT = scrambled control siRNA. Densitometric quantification of each protein relative to a-tubulin is shown below each band

\section{HNSCC PDX models develop resistance to alpelisib}

In parallel with our cell line models, we generated 5 PDX models from HNSCC patient tumors (clinical characteristics outlined in Additional Table 4). Of the 5 models, one (PDX-B) was both HPV-positive and contained a non-synonymous PIK3CA mutation (E545K) [21]. The remaining models were all PIK3CA wildtype. Several of the PDX models contained mutations frequently seen in HNSCC, including TP53 mutations, EGFR amplifications and CDKN2A alterations [4, 21]. Histological comparison of PDXs and their corresponding primary tumors (where available) revealed a high degree of similarity in their cellular morphology (Additional Fig. 5). In all 5 PDX models, treatment with alpelisib significantly suppressed tumor growth for the first 20-35 days, relative to the vehicle agent (Fig. 4a, boxed regions). However, beyond this initial response period, alpelisib-treated tumors began to resume growth or exhibit an increased rate of growth over time (Fig. 4a). Thus, PDX models behave similarly to cell lines in that they also spontaneously develop resistance to $\mathrm{PI} 3 \mathrm{~K} \alpha$ inhibition by alpelisib over time.

Ki67 staining was used to examine the proliferative activity of vehicle-treated tumors, alpelisib-sensitive tumors (not treated to resistance) and alpelisib-resistant tumors. Most vehicle-treated and alpelisib-resistant tumors exhibited strong positive Ki67 staining, whereas alpelisibsensitive tumors showed weaker staining (representative sections shown in Additional Fig. 6). We next analyzed the expression of AXL and TYRO3 in PDX models using IHC. While no difference in AXL expression was detected for either model examined (Additional Fig. 7), TYRO3 expression following prolonged treatment with alpelisib was elevated in both PDX models (Fig. 4b).

\section{TYRO3 and AXL overexpression mediates resistance to alpelisib}

Since expression of AXL and TYRO3 were both elevated in alpelisib-resistant models, we proceeded to determine the relative expression of both receptors at the cell surface in parental and resistant cells. Flow cytometric analysis demonstrated a significant increase in both AXL and TYRO3 surface levels in alpelisib-resistant Cal33 and 93VU-147T cells, compared to parental cells (Fig. 5a).

To assess whether the upregulation of TYRO3 and/or AXL expression plays a causative role in mediating resistance to PI3K $\alpha$ inhibition, we used siRNAs to silence each receptor in alpelisib-resistant cells. Knockdown of either TYRO3 or AXL re-sensitized resistant cells to alpelisib treatment, to a level almost comparable to their parental (baseline) sensitivity (Fig. 5b). In 93-VU-147T cells, combined TYRO3 and AXL knockdown sensitized resistant cells to an even greater extent than their parental sensitivity, highlighting the role both receptors play in modulating response to alpelisib treatment.

MAPK signalling is activated in alpelisib-resistant models Since the expression of activated MAPK pathway members ERK1/2 and P90RSK was reduced by PI3K inhibition in parental cells (Fig. 1a) and the MAPK signalling pathway is a downstream target associated with TAM RTKs, we proceeded to examine the activation status of several MAPK pathway members in our resistant cells (Fig. 6a) [33]. Beginning upstream, we examined expression of the scaffold protein GAB2 that mediates signalling from the adaptor protein Grb2 on intracellular RTK domains to RAS. GAB2 expression was elevated in alpelisib-resistant 93-VU-147T cells (as suggested in the RPPA), although no difference was apparent in Cal33 cells (Fig. 6b, block 1). The next differentially-expressed pathway member was phosphorylated MEK1 (Ser298) which was apparent in alpelisib-resistant Cal33 cells (Fig. 6b, block 2). Moving down the MAPK pathway, elevated activating phosphorylation of ERK1/2 and P90RSK was detected in all alpelisibresistant cell lines (Fig. 6b, block 3 ). Collectively, these observations reveal an induction of MAPK pathway activation upon prolonged treatment with alpelisib.

Given the upregulation of pP90RSK (Ser380) observed in the resistant cell lines and its described involvement in HNSCC oncogenesis, we proceeded to examine its expression in our PDX models using IHC $[35,36]$. We observed a non-significant trend towards elevated pP90RSK (Ser380) expression in alpelisib-resistant PDX-E tissues and a significant increase in expression in PDX-C tissues (Fig. 6c-d).

\section{Inhibition of MAPK signalling improves response to alpelisib}

To evaluate the effect of MAPK signalling on resistant cells' responsiveness to alpelisib, we targeted the downstream MAPK pathway member P90RSK using the small molecule inhibitor BI-D1870, alone and in combination with alpelisib [37]. In both alpelisib-resistant cell lines, BI-D1870 treatment resulted in a significant reduction in cell viability (Fig. 7a). 
A.

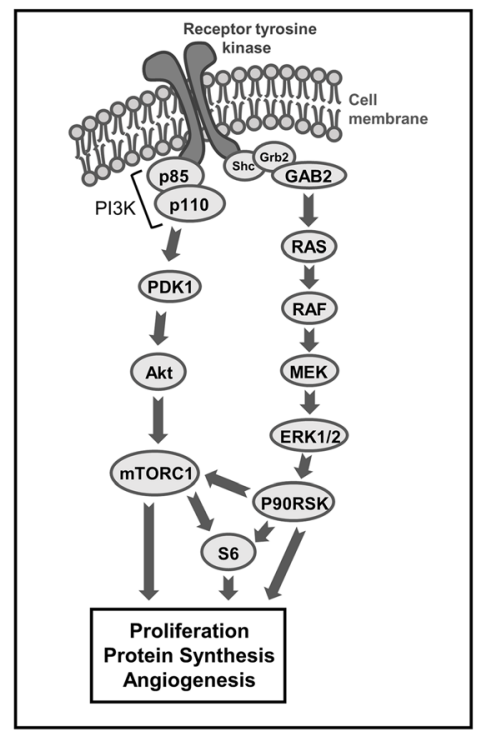

C.

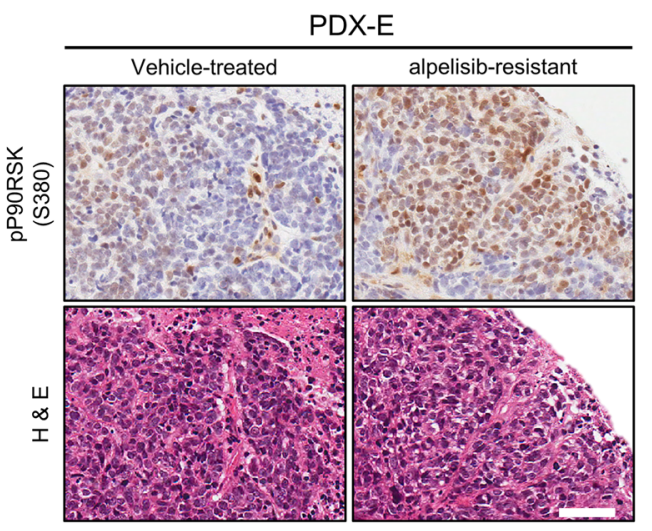

D.

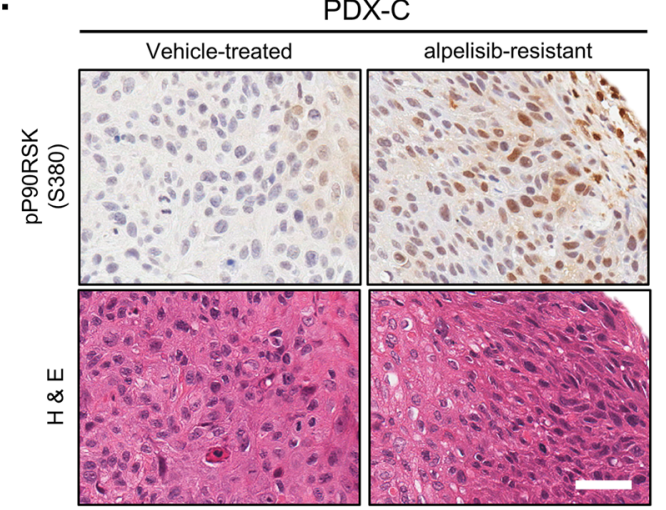

B.
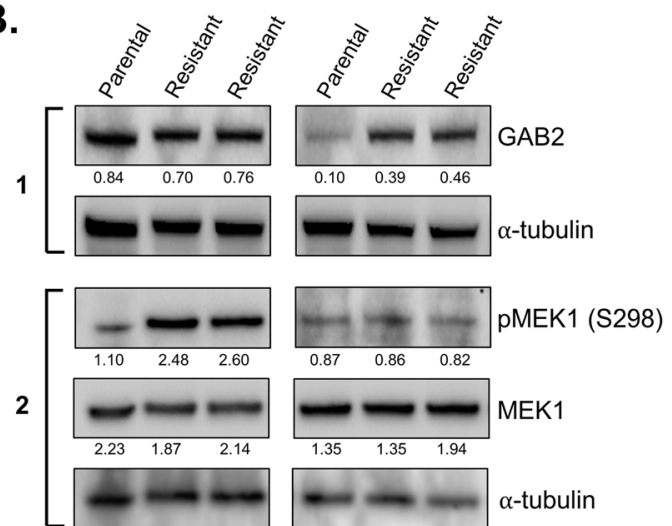

3
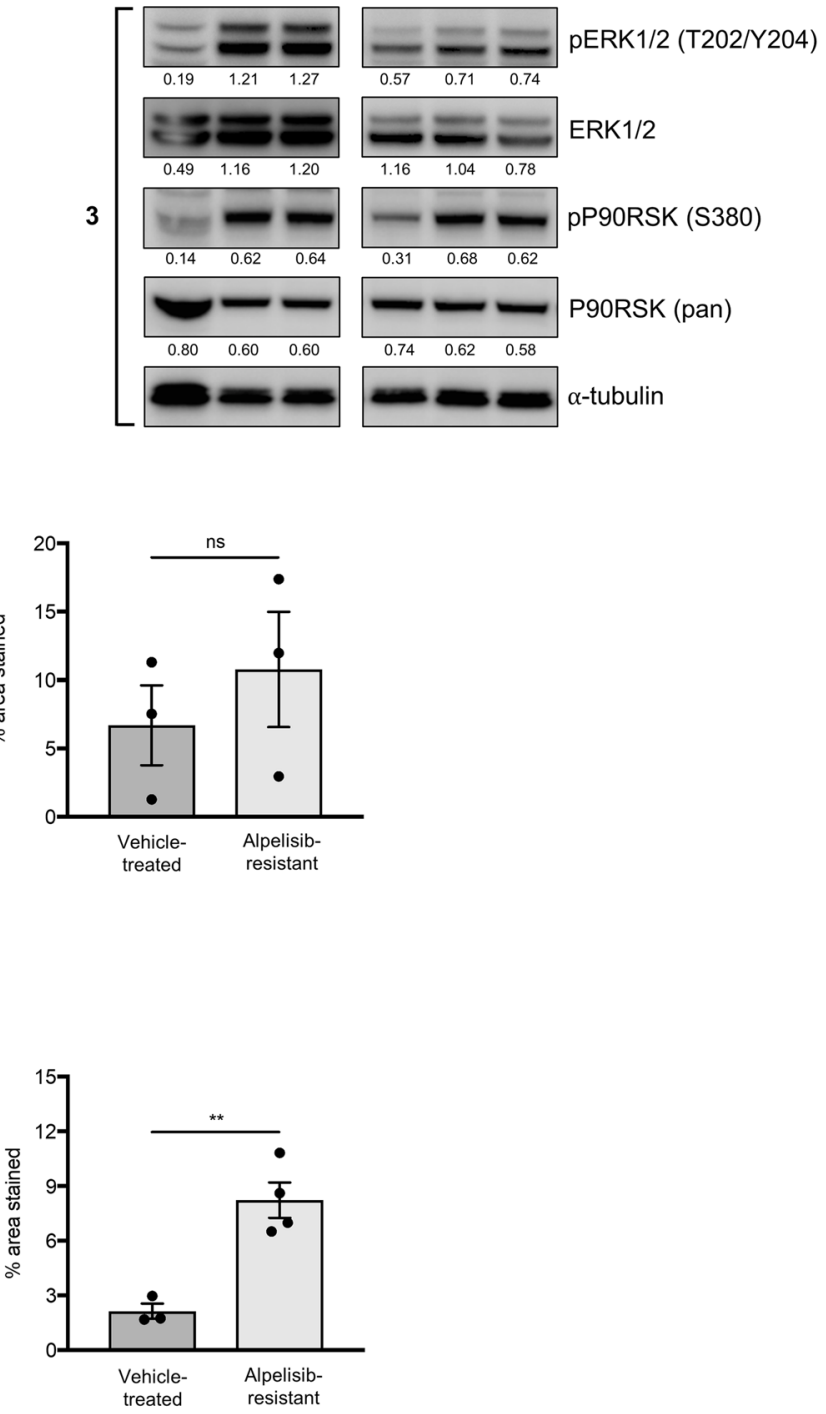

Fig. 6 (See legend on next page.) 
(See figure on previous page.)

Fig. 6 Activation of the MAPK signalling pathway in alpelisib-resistant cell lines and PDX models. a Schematic representation of PI3K and MAPK pathways, with crosstalk activating mTORC1 shown. $\mathbf{b}$ Immunoblot with indicated parental and alpelisib-resistant lysates examining activation of the MAPK pathway. Densitometric quantification of each protein relative to a-tubulin is shown below each band. c \& d Representative IHC sections showing PP90RSK (Ser380) staining in PDX-E c and PDX-C $\mathbf{d}$ models. Quantification was completed using Fiji software and is shown below. ${ }^{* * *}$ represent $p<0.01$, ns $=$ not significant, unpaired Student's $t$-test. Scale bars represent $50 \mu \mathrm{M}$

When BI-D1870 and alpelisib treatments were combined, greater decreases in cell viability were observed.

\section{Knockdown of TYRO3 and AXL reduces MAPK pathway activation}

We next evaluated the relation between expression of TYRO3 and AXL, and MAPK pathway activation. Following knockdown of TYRO3 and AXL in alpelisibresistant cells, we used immunoblotting to detect phosphorylated (active form) members of the MAPK pathway, including ERK1/2, P90RSK and S6 (Fig. 7b). In Cal33 cells, silencing of either TYRO3 or AXL was associated with reduced phosphorylation of P90RSK (Ser380) and S6 (Ser235/6), while only TYRO3 silencing reduced ERK1/2 (Thr202/Tyr204) phosphorylation. In 93-VU-147T cells, TYRO3 knockdown reduced phosphorylation of ERK1/2 and P90RSK, while AXL knockdown did not have an apparent effect on MAPK pathway activation.

\section{Baseline expression of AXL and TYRO3 is not associated with sensitivity to PI3K inhibition}

To determine whether expression of TYRO3 and/or AXL was associated with PI3K inhibitor sensitivity at baseline (without prolonged drug exposure), we examined the protein expression of both receptors in a panel of 25 HNSCC cell lines (Additional Table 1) [20]. We previously characterized the sensitivity of all 25 lines to alpelisib and ordered the cell lines accordingly [21]. While expression of both proteins varied between cell lines, we did not observe a trend in the expression of either TYRO3 or AXL that appeared to correlate with sensitivity to alpelisib (Additional Fig. 8). Given an absence of a correlation between baseline TAM RTK expression and response to PI3K inhibition, it appears the involvement of TYRO3 and AXL in drug response is contingent on either the activity of the receptors or a relative upregulation of receptors during the course of treatment that subsequently affects drug response.

\section{Activation of MAPK signalling and elevated TAM RTK expression in a PDX-derived cell line}

Finally, in parallel with our in vitro and in vivo models of acquired resistance to PI3K inhibition, we treated our PDX-derived cell line (PDX-C cell line) with alpelisib to generate an alpelisib-resistant cell line. This model system provided the unique opportunity to use an early-passage tumor-derived cell line to validate the data from both our in vitro studies using established HNSCC cell lines and our in vivo studies using PDX models. The alpelisibresistant PDX-C-derived cell line had $\mathrm{a} \sim 3$-fold increase in IC50 $(2.3 \mu \mathrm{M}$ versus $6.3 \mu \mathrm{M})$, relative to its parental counterpart (Fig. 7c). Immunoblotting revealed elevated expression of AXL in the alpelisib-resistant cell line, while TYRO3 expression appeared stable (Fig. 7d). We proceeded to evaluate the relative expression of AXL and TYRO3 at the cell surface using flow cytometry. We observed a significant increase in AXL surface levels in alpelisib-resistant PDX-C cells, compared to in parental cells (Fig. 7e). Downstream, elevated phosphorylation of MAPK pathway members ERK1/2 and P90RSK was also detected in alpelisib-resistant PDX-C cells, confirming our previous in vitro and in vivo PDX findings (Fig. 7f).

\section{Discussion}

In this study, we demonstrate that PI3K $\alpha$ inhibition exhibits anti-tumor efficacy in HNSCC models by dampening PI3K signalling, inducing PARP cleavage and reducing the proportion of actively-proliferating cells. As targeted PI3K $\alpha$ inhibition is under active clinical investigation for HNSCC patients and has been FDA-approved for breast cancer treatment already, we proceeded to evaluate the efficacy of PI3K $\alpha$ inhibition over time. We show in both in vitro and in vivo assays that HNSCC escapes the anti-tumor activity of alpelisib over a period of weeks to months. This acquisition of drug resistance is associated with upregulation of the RTKs TYRO3 and AXL, and an increase in signalling through the MAPK network. While AXL has been described in various settings to function as a mediator of acquired drug resistance, the involvement of its family member TYRO3 is previously unrecognized [12, 26, 27, 38, 39].

AXL and TYRO3 are two members of the threemembered TAM family of RTKs, which also includes MERTK [32]. Although none of the TAM RTKs are considered to be strong oncogenes, all three have demonstrated transforming potential and it is increasingly recognized that their overexpression contributes to resistance to both standard and targeted chemotherapies [31, 40]. AXL is by far the beststudied TAM RTK and has an established role in supporting tumorigenesis through its positive effects on cellular survival, migration, proliferation and invasion, and in mediating acquired resistance [31]. To date, overexpression of AXL has 


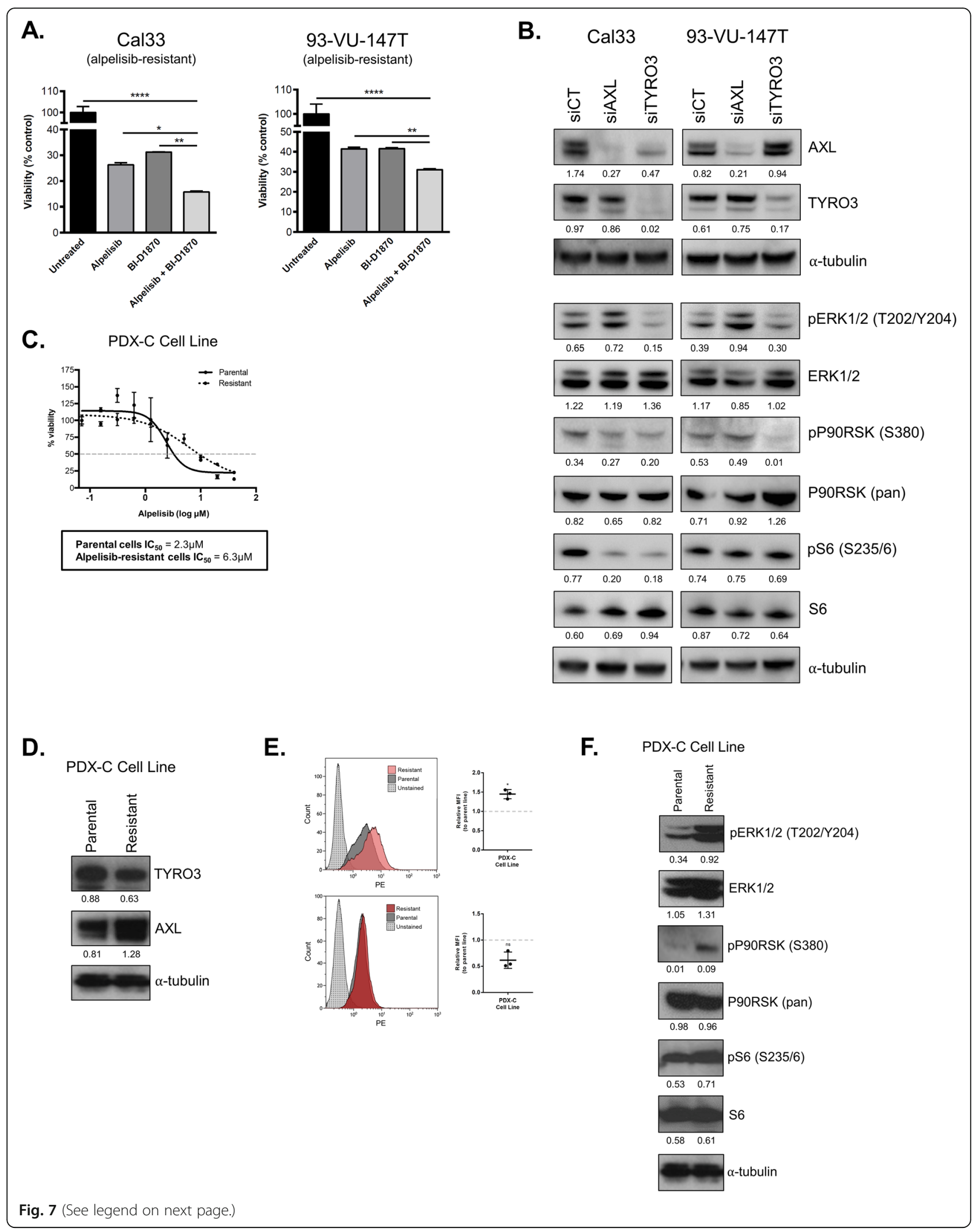




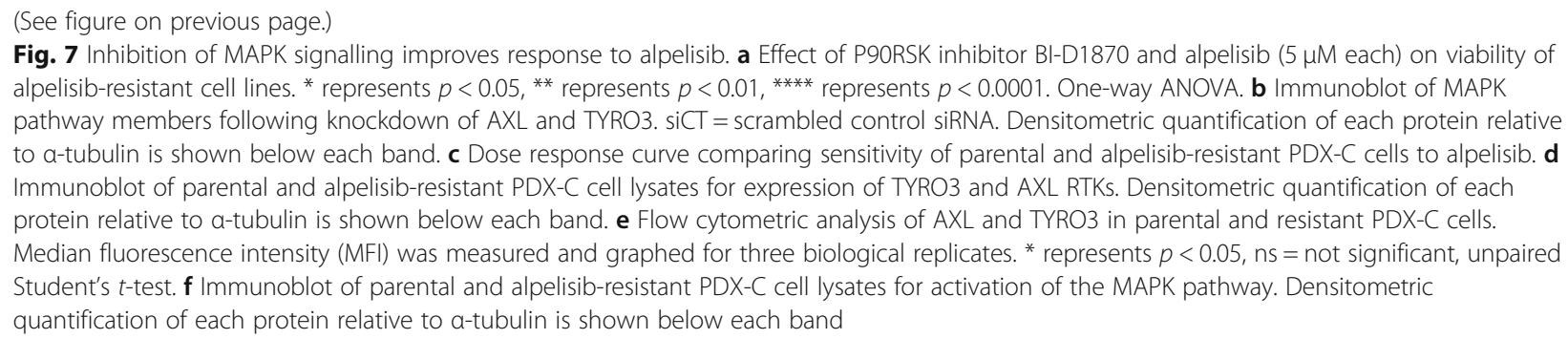

been implicated in resistance to imatinib (BCR-Abl, c-Kit and PDGFR inhibitor), lapatinib (HER2 inhibitor), erlotinib (EGFR inhibitor) and cetuximab (EGFR-targeting monoclonal antibody), as well as resistance to the chemotherapeutics doxorubicin, cisplatin and etoposide (VP-16) in a variety of solid tumor types and blood cancers [26, 27, 31, 38, 39, 41, 42]. In contrast, TYRO3 overexpression has been shown to mediate taxol resistance in ovarian cancer and in general, promote progression of various cancers when overexpressed $[31,34,43,44]$.

In our HNSCC models, upregulation of both AXL and TYRO3 total protein was detected, as was an increase in cell surface localization in alpelisib-resistant versus parental samples. The involvement of AXL and TYRO3 in resistance to PI3K $\alpha$ inhibition is underscored by the fact that knockdown of either or both receptors significantly sensitized cells to alpelisib treatment.

Across a large panel of HNSCC cell lines, we did not observe a trend between protein expression of TYRO3 or AXL, and sensitivity to PI3Ka inhibition. This leads us to believe that the involvement of AXL and TYRO3 in PI3K inhibitor resistance is likely based on a relative increase in expression/surface localization or altered receptor activity, rather than a baseline expression level. At present it is not well known how expression of AXL and TYRO3 is regulated; given the emerging role of TAM RTKs in cancer and drug response however, this is an area of active research [32, 33]. Hypoxia and HIF$1 \alpha$ expression has been associated with AXL expression while certain microRNAs (miRNAs) are also thought to be a mediator of TAM RTK expression [45-48].

Downstream of AXL and TYRO3, numerous intracellular signalling pathways have been associated with cancer progression and drug resistance [32, 33]. Reactivation of Akt signalling and activation of the NF- $k B$ pathway are two such examples [38, 39]. In the context of HNSCC specifically, PLC $\gamma$-PKC signalling downstream of AXL has been identified following PI3K $\alpha$ inhibition [12]. Our data provide evidence of MAPK pathway activation, consistent across both cell lines surveyed. Further, targeted inhibition of the downstream MAPK pathway member P90RSK, alone and in combination with alpelisib, resulted in a significant reduction in cell viability of alpelisib-resistant HNSCC cells, emphasizing the relevance of this pathway in circumventing PI3K inhibition. Our observations are in accordance with previous findings that have demonstrated RSK family members to be mediators of resistance to PI3K pathway inhibition in breast cancer, and to be capable of promoting disease progression in HNSCC specifically $[35,36]$.

Other studies have reported that residual mTORC1 activity following PI3K inhibition is involved with limiting its anti-tumor efficacy [49,50]. The activation of MAPK signalling observed in our alpelisib-resistant HNSCC cell lines supports this finding, as the MAPK pathway intersects with the PI3K pathway at several downstream points that promote mTORC1 or S6 activity (Fig. 7a) [51]. As well, Chandarlapaty et al. (2011) described a direct association between inhibition of PI3K/ Akt signalling and upregulation of RTKs, such as HER3 and IGF-1R [52]. The pattern of receptor upregulation/ activation and intracellular signalling converging on mTORC1/S6 may be a shared feature of acquired resistance to PI3K pathway inhibition across different cancer types [12, 52]. However, the particular mechanism and mediator(s) adopted by tumor cells are likely cancerand/or drug-specific.

Recently, PDX models have emerged as a leading preclinical platform through which to interrogate drug efficacy, interpatient response heterogeneity and, more recently, to elucidate mechanisms of drug resistance [18, 53, 54]. In our study, we confirmed in vitro findings of TYRO3 and AXL upregulation and MAPK pathway activation upon prolonged PI3K $\alpha$ inhibition in a panel of 5 unique HNSCC PDX models treated for up to 100 days with alpelisib.

Based on our collective findings, pan-TAM inhibition emerges as a logical combinatorial or second-line treatment target alongside PI3K $\alpha$ inhibition in HNSCC. While AXL inhibitors are already in active development owing to its identified role in drug resistance, our findings reveal its family member TYRO3 to be similarly relevant [31]. The importance of TYRO3 is particularly evident through our in vivo models, where we found TYRO3 protein expression to be significantly upregulated in alpelisib-resistant PDX tissues, whereas the changes in AXL expression were less apparent. We 
would therefore speculate that the use of a dual AXL/ TYRO3 or pan-TAM inhibitor (e.g. LDC1267) would be more effective and durable over time [31]. To date, nospecific TYRO3 inhibitors are available. Targeting the MAPK pathway is an alternative approach, as we demonstrated with the P90RSK inhibitor BI-D1870. However, MAPK pathway inhibition has had variable efficacy to date and acquired resistance to inhibitors of the MAPK pathway has been documented, in some cases involving TAM RTKs $[55,56]$. Upstream targeting of AXL and TYRO3 therefore seems to be the most logical approach. Importantly, as AXL has been identified as a drug resistance mediator to PI3K inhibition in several cancer types, pan-TAM inhibition may be a sensible approach to preventing resistance in settings even beyond HNSCC; this is a key area for future study.

\section{Conclusion}

In summary, our findings identify TYRO3/AXL upregulation and MAPK pathway activation as a consequence of prolonged PI3K $\alpha$ inhibition, both in vitro and in vivo. A therapeutic approach involving not only AXL inhibition, but pan-TAM RTK inhibition may therefore help to prevent, or at least delay, resistance to PI3K inhibitors and improve outcomes for HNSCC patients.

\section{Supplementary information}

Supplementary information accompanies this paper at https://doi.org/10. 1186/s13046-020-01713-9.

Additional file 1. Supplemental Tables \& Figures. Additional Table 1. Sources and cell culture media for established HNSCC cell lines used in this study. Additional Table 2. Short-tandem repeat (STR) profiling results confirming matching identities of primary tumor, blood, xenograft tumors and cell lines, where available. Additional Table 3. Antibodies used in this study. Additional Table 4. Clinical features of HNSCC patients used to generate PDX models of acquired drug resistance. Additional Fig. 1. (A) Schematic outlining the derivation of cell line from PDX-C. (B) Phase contrast microscopy image of PDX-C cells. (C) Flow cytometry for cell surface expression of EpCAM (CD326) in PDX-C cells. Over 99\% of PDX-C cells were found to be CD326-positive. Additional Fig. 2. Schematic outlining the development of the alpelisib-resistant HNSCC cell lines. Parental cells (Cal33 and 93-VU-147T) were treated with increasing doses of alpelisib, beginning with their IC50 values $(0.5 \mu \mathrm{M}$ for Cal33, $1.7 \mu \mathrm{M}$ for 93-VU-147T), as previously established [20]. Additional Fig. 3. Relative abundance of small, medium and large sized colonies for parental and alpelisib-resistant cell lines ((A) Cal33 cells, (B) 93-VU-147T cells) when untreated, and when treated with alpelisib. Colony counts and sizes were analyzed in ImageJ version 1.52a. Briefly, RGB images of wells were converted in binary images and analyzed using the Analyze Particles feature. Colony size cutoffs were set as follows (in pixels): Small 0100; Medium 101-500; Large $\geq 501$. Additional Fig. 4. (A) \& (B) Immunoblot of MER-TK expression in parental and alpelisib-resistant Cal33 and 93-VU-147T cells. Short and long exposures of MER-TK blot are shown. HEK293T cells served as a positive control for MER-TK expression. Additional Fig. 5. Histological comparison of PDX tissues and their corresponding primary tumors (where available), stained with H\&E. Scale bar represents $50 \mu \mathrm{M}$. Additional Fig. 6. Representative IHC sections showing Ki67 staining PDX tissues treated with the vehicle agent (corn oil) or alpelisib (endpoint either while still responding or treated out to the emergence of resistance). Scale bar represents $100 \mu$ M. Additional Fig.
7. Representative $I H C$ sections showing $A X L$ staining in PDX-C and PDX-E models. Quantification completed using Fiji software is shown below. ns $=$ not significant, unpaired Student's $t$-test. Scale bars represent $100 \mu \mathrm{M}$. Additional Fig. 8. Immunoblot of TYRO3 and AXL expression in 25 HNSCC cell lines, ordered by sensitivity to alpelisib $\left({ }^{\prime} C_{50}\right.$ values indicated).

Additional file 2. Supplemental Methods \& Materials.

\section{Abbreviations}

FBS: Fetal bovine serum; FDA: Food and Drug Administration; H \&

E: Hematoxylin \& eosin; HNSCC: Head and neck squamous cell carcinoma; $I_{50}$ : Half-maximal inhibitory concentration values:

IHC: Immunohistochemistry; MeOH: Methanol; miRNA: microRNA; MTA-

1: Manual Tissue Arrayer; PDX: Patient-derived xenografts;

PI3K: Phosphatidylinositol 3-kinase; RPPA: Reverse phase protein array

RTK: Receptor tyrosine kinase; SD: Standard deviation; SDS: Sodium dodecyl sulfate; Ser: Serine; siCT: Scrambled control siRNA; TAM: TYRO3, AXL, MER-TK; Thr: Threonine; Tyr: Tyrosine

\section{Acknowledgements}

Not applicable.

\section{Authors' contributions}

All experiments were performed by KMR, except for animal drug administration and tumor measurements (completed by JM and LA), and IHC staining (a collaboration between PP, WS, CJH and the Dept. of Pathology \& Laboratory Medicine Core Facility at Western University). All authors were involved in study design and manuscript preparation. All author(s) read and approved the final manuscript.

\section{Funding}

This study was funded by a Canadian Institutes for Health Research (CIHR) grant MOP 340674 to ACN and PCB. PCB was supported by CIHR and Terry Fox Research New Investigator Awards and by the Ontario Institute for Cancer Research. ACN was supported by the Wolfe Surgical Research Professorship in the Biology of Head and Neck Cancers Fund.

\section{Availability of data and materials}

All data generated or analyzed during this study are included in this published article (and its supplementary information files).

\section{Ethics approval and consent to participate}

Mice were handled in accordance with the AUP 1542 approved by the University Health Network Animal Care Committee and in accordance with the CCAC regulations.

Consent for publication

Not applicable.

\section{Competing interests}

ACN has received clinical trial funding from Novartis for a Window of Opportunity Trial using alpelisib in HNSCC patients (NCT03138070).

\section{Author details}

${ }^{1}$ Department of Otolaryngology - Head and Neck Surgery, Schulich School of Medicine \& Dentistry, Western University, Room B3-431A, 800 Commissioners Road East, London, ON N6A 5W9, Canada. ${ }^{2}$ Department of Pathology \& Laboratory Medicine, Schulich School of Medicine \& Dentistry, Western University, London, ON, Canada. ${ }^{3}$ Princess Margaret Cancer Centre, University Health Network, Toronto, ON, Canada. ${ }^{4}$ Department of Oncology, Schulich School of Medicine \& Dentistry, Western University, London, ON, Canada. ${ }^{5}$ Department of Microbiology and Immunology, Schulich School of Medicine \& Dentistry, Western University, London, ON, Canada. ${ }^{6}$ Eli and Edythe Broad Center of Regenerative Medicine and Stem Cell Research, University of California, Los Angeles, CA, USA. Institute for Precision Health, University of California, Los Angeles, CA, USA. ${ }^{8}$ Jonsson Comprehensive Cancer Centre, University of California, Los Angeles, CA, USA. ${ }^{9}$ Department of Medical Biophysics, University of Toronto, Toronto, ON, Canada. 
Received: 16 January 2020 Accepted: 16 September 2020 Published online: 15 October 2020

\section{References}

1. Jemal A, Bray F, Center MM, Ferlay J, Ward E, Forman D. Global cancer statistics. CA Cancer J Clin. 2011;61(2):69-90.

2. Machtay M, Moughan J, Trotti A, Garden AS, Weber RS, Cooper JS, et al. Factors associated with severe late toxicity after concurrent chemoradiation for locally advanced head and neck cancer: an RTOG analysis. J Clin Oncol. 2008;26(21):3582-9.

3. Ocana A, Vera-Badillo F, Al-Mubarak M, Templeton AJ, Corrales-Sanchez V, Diez-Gonzalez L, et al. Activation of the PI3K/mTOR/AKT pathway and survival in solid tumors: systematic review and meta-analysis. PLoS One. 2014;9(4):e95219.

4. Cancer Genome Atlas N. Comprehensive genomic characterization of head and neck squamous cell carcinomas. Nature. 2015;517(7536):576-82.

5. Engelman JA. Targeting PI3K signalling in cancer: opportunities, challenges and limitations. Nat Rev Cancer. 2009;9(8):550-62.

6. Liu P, Cheng H, Roberts TM, Zhao JJ. Targeting the phosphoinositide 3kinase pathway in cancer. Nat Rev Drug Discov. 2009:8(8):627-44.

7. Rodon J, Dienstmann R, Serra V, Tabernero J. Development of PI3K inhibitors: lessons learned from early clinical trials. Nat Rev Clin Oncol. 2013; 10(3):143-53.

8. Juric D, Rodon J, Tabernero J, Janku F, Burris H, Schellens J, et al. Phosphatidylinositol 3-kinase a-selective inhibition with Alpelisib (BYL719) in PIK3CA-altered solid tumors: results from the first-in-human study. J Clin Oncol. 2018;36:361-72.

9. Juric D, Castel $\mathrm{P}$, Griffith $\mathrm{M}$, Griffith $\mathrm{OL}$, Won $\mathrm{HH}$, Ellis $\mathrm{H}$, et al. Convergent loss of PTEN leads to clinical resistance to a PI (3) Kalpha inhibitor. Nature. 2015;518(7538):240-4.

10. Castel P, Ellis H, Bago R, Toska E, Razavi P, Carmona FJ, et al. PDK1-SGK1 signaling sustains AKT-independent MTORC1 activation and confers resistance to PI3Kalpha inhibition. Cancer Cell. 2016:30(2):229-42.

11. Muranen T, Selfors LM, Worster DT, Iwanicki MP, Song L, Morales FC, et al. Inhibition of $\mathrm{PI} 3 \mathrm{~K} / \mathrm{mTOR}$ leads to adaptive resistance in matrix-attached cancer cells. Cancer Cell. 2012;21(2):227-39.

12. Elkabets $M$, Pazarentzos $E$, Juric $D$, Sheng $Q$, Pelossof RA, Brook S, et al. AXL mediates resistance to PI3Kalpha inhibition by activating the EGFR/PKC/ mTOR axis in head and neck and esophageal squamous cell carcinomas. Cancer Cell. 2015;27(4):533-46.

13. Muranen T, Selfors LM, Hwang J, Gallegos LL, Coloff JL, Thoreen CC, et al. ERK and p38 MAPK activities determine sensitivity to PI3K/mTOR inhibition via regulation of MYC and YAP. Cancer Res. 2016;76(24):7168-80.

14. Ruicci KM, Plantinga P, Pinto N, Khan Ml, Stecho W, Dhaliwal SS, et al. Disruption of the RICTOR/mTORC2 complex enhances the response of head and neck squamous cell carcinoma cells to PI3K inhibition. Mol Oncol. 2019; 13(10):2160-77.

15. Yun MR, Choi HM, Kang HN, Lee $Y$, Joo HS, Kim DH, et al. ERK-dependent IL6 autocrine signaling mediates adaptive resistance to pan-PI3K inhibitor BKM120 in head and neck squamous cell carcinoma. Oncogene. 2018;37(3): 377-88

16. Janku F. Phosphoinositide 3-kinase (PI3K) pathway inhibitors in solid tumors: from laboratory to patients. Cancer Treat Rev. 2017:59:93-101.

17. Fritsch C, Huang A, Chatenay-Rivauday C, Schnell C, Reddy A, Liu M, et al, Characterization of the novel and specific PI3Kalpha inhibitor NVP-BYL719 and development of the patient stratification strategy for clinical trials. Mol Cancer Ther. 2014;13(5):1117-29.

18. Gao H, Korn JM, Ferretti S, Monahan JE, Wang Y, Singh M, et al. Highthroughput screening using patient-derived tumor xenografts to predict clinical trial drug response. Nat Med. 2015;21(11):1318-25.

19. Groenendijk FH, Bernards R. Drug resistance to targeted therapies: deja vu all over again. Mol Oncol. 2014;8(6):1067-83.

20. Ghasemi FBM, Sun RX, Vizeacoumar F, Pinto N, Ruicci KM, Yoo J, Fung K, MacNeil D, Palma DA, Winquist E, Mymryk JS, Ailles LA, Datti A, Barrett JW, Boutros PC, Nichols AC. High-throughput testing in head and neck squamous cell carcinoma identifies agents with preferential activity in human papillomavirus-positive or negative cell lines. Oncotarget. 2018;9(40):26064-71.

21. Ruicci KM, Meens J, Sun RX, Rizzo G, Pinto N, Yoo J, et al. A controlled trial of HNSCC patient-derived xenografts reveals broad efficacy of PI3Kalpha inhibition in controlling tumor growth. Int J Cancer. 2019;145(8):2100-6.
22. McDermott M, Eustace AJ, Busschots S, Breen L, Crown J, Clynes M, et al. In vitro development of chemotherapy and targeted therapy drug-resistant Cancer cell lines: a practical guide with case studies. Front Oncol. 2014;4:40.

23. Ruicci KM, Pinto N, Khan MI, Yoo J, Fung K, MacNeil D, et al. ERK-TSC2 signalling in constitutively-active HRAS mutant HNSCC cells promotes resistance to PI3K inhibition. Oral Oncol. 2018:84:95-103.

24. Meister KS, Godse NR, Khan NI, Hedberg ML, Kemp C, Kulkarni S, et al. HER3 targeting potentiates growth suppressive effects of the PI3K inhibitor BYL719 in pre-clinical models of head and neck squamous cell carcinoma. Sci Rep. 2019;9(1):9130.

25. Keam B, Kim S, Ahn YO, Kim TM, Lee SH, Kim DW, et al. In vitro anticancer activity of PI3K alpha selective inhibitor BYL719 in head and neck cancer. Anticancer Res. 2015:35(1):175-82.

26. Zhang Z, Lee JC, Lin L, Olivas $V$, Au V, LaFramboise T, et al. Activation of the AXL kinase causes resistance to EGFR-targeted therapy in lung cancer. Nat Genet. 2012;44(8):852-60.

27. Liu L, Greger J, Shi H, Liu Y, Greshock J, Annan R, et al. Novel mechanism of lapatinib resistance in HER2-positive breast tumor cells: activation of AXL. Cancer Res. 2009;69(17):6871-8.

28. Byers LA, Diao L, Wang J, Saintigny P, Girard L, Peyton M, et al. An epithelial-mesenchymal transition gene signature predicts resistance to EGFR and PI3K inhibitors and identifies AxI as a therapeutic target for overcoming EGFR inhibitor resistance. Clin Cancer Res. 2013;19(1):279-90.

29. Lemke G. Biology of the TAM receptors. Cold Spring Harb Perspect Biol. 2013;5(11):a009076.

30. Davra V, Kimani SG, Calianese D, Birge RB. Ligand Activation of TAM Family Receptors-Implications for Tumor Biology and Therapeutic Response. Cancers (Basel). 2016;8(12):107-21.

31. Vouri M, Hafizi S. TAM receptor tyrosine kinases in Cancer drug resistance. Cancer Res. 2017:77(11):2775-8.

32. Graham DK, DeRyckere D, Davies KD, Earp HS. The TAM family: phosphatidylserine sensing receptor tyrosine kinases gone awry in cancer. Nat Rev Cancer. 2014;14(12):769-85

33. Linger RMA, Keating AK, Earp HS, Graham DK. TAM receptor tyrosine kinases: biologic functions, signaling, and potential therapeutic targeting in human Cancer. Adv Cancer Res. 2008:100:35-83.

34. Smart SK, Vasileiadi E, Wang X, DeRyckere D, Graham DK. The Emerging Role of TYRO3 as a Therapeutic Target in Cancer. Cancers (Basel). 2018:10(12):474-501.

35. Serra V, Eichhorn PJ, Garcia-Garcia C, Ibrahim YH, Prudkin L, Sanchez G, et al. RSK3/4 mediate resistance to PI3K pathway inhibitors in breast cancer. J Clin Invest. 2013;123(6):2551-63.

36. Kang S, Elf S, Lythgoe K, Hitosugi T, Taunton J, Zhou W, et al. p90 ribosomal S6 kinase 2 promotes invasion and metastasis of human head and neck squamous cell carcinoma cells. J Clin Invest. 2010;120(4):1165-77.

37. Chiu CF, Bai LY, Kapuriya N, Peng SY, Wu CY, Sargeant AM, et al. Antitumor effects of BI-D1870 on human oral squamous cell carcinoma. Cancer Chemother Pharmacol. 2014:73(2):237-47.

38. Brand TM, lida M, Stein AP, Corrigan KL, Braverman CM, Luthar N, et al. AXL mediates resistance to cetuximab therapy. Cancer Res. 2014:74(18):5152-64.

39. Giles KM, Kalinowski FC, Candy PA, Epis MR, Zhang PM, Redfern AD, et al. Axl mediates acquired resistance of head and neck cancer cells to the epidermal growth factor receptor inhibitor erlotinib. Mol Cancer Ther. 2013;12(11):2541-58.

40. McDaniel NK, Cummings CT, lida M, Hulse J, Pearson HE, Vasileiadi E, et al. MERTK mediates intrinsic and adaptive resistance to AXL-targeting agents. Mol Cancer Ther. 2018:17(11):2297-308.

41. Hong CC, Lay JD, Huang JS, Cheng AL, Tang JL, Lin MT, et al. Receptor tyrosine kinase $\mathrm{AXL}$ is induced by chemotherapy drugs and overexpression of $A X L$ confers drug resistance in acute myeloid leukemia. Cancer Lett. 2008;268(2):314-24.

42. Lee C. Overexpression of Tyro3 receptor tyrosine kinase leads to the acquisition of taxol resistance in ovarian cancer cells. Mol Med Rep. 2015; 12(1):1485-92.

43. Dantas-Barbosa C, Lesluyes T, Loarer FL, Chibon F, Treilleux I, Coindre JM, et al. Expression and role of TYRO3 and AXL as potential therapeutical targets in leiomyosarcoma. Br J Cancer. 2017;117(12):1787-97.

44. Duan Y, Wong W, Chua SC, Wee HL, Lim SG, Chua BT, et al. Overexpression of Tyro3 and its implications on hepatocellular carcinoma progression. Int J Oncol. 2016:48(1):358-66.

45. Mishra A, Wang J, Shiozawa Y, McGee S, Kim J, Jung Y, et al. Hypoxia stabilizes GAS6/Axl signaling in metastatic prostate cancer. Mol Cancer Res. 2012;10(6):703-12. 
46. Nalwoga $H$, Ahmed L, Arnes JB, Wabinga H, Akslen LA. Strong expression of hypoxia-inducible factor-1alpha (HIF-1alpha) is associated with Axl expression and features of aggressive tumors in African breast Cancer. PLoS One. 2016;11(1):e0146823.

47. Mackiewicz M, Huppi K, Pitt JJ, Dorsey TH, Ambs S, Caplen NJ. Identification of the receptor tyrosine kinase AXL in breast cancer as a target for the human miR-34a microRNA. Breast Cancer Res Treat. 2011;130(2):663-79.

48. Mudduluru G, Ceppi P, Kumarswamy R, Scagliotti GV, Papotti M, Allgayer H. Regulation of Axl receptor tyrosine kinase expression by miR-34a and miR199a/b in solid cancer. Oncogene. 2011;30(25):2888-99.

49. Elkabets M, Vora S, Juric D, Morse N, Mino-Kenudson M, Muranen T, et al. mTORC1 inhibition is required for sensitivity to PI3K p110alpha inhibitors in PIK3CA-mutant breast cancer. Sci Transl Med. 2013;5(196):196ra99.

50. Guri Y, Hall MN. mTOR signaling confers resistance to targeted Cancer drugs. Trends Cancer. 2016;2(11):688-97.

51. Mendoza MC, Er EE, Blenis J. The Ras-ERK and PI3K-mTOR pathways: crosstalk and compensation. Trends Biochem Sci. 2011;36(6):320-8.

52. Chandarlapaty S, Sawai A, Scaltriti M, Rodrik-Outmezguine V, Grbovic-Huezo $\mathrm{O}$, Serra $\mathrm{V}$, et al. AKT inhibition relieves feedback suppression of receptor tyrosine kinase expression and activity. Cancer Cell. 2011;19(1):58-71.

53. Rosfjord E, Lucas J, Li G, Gerber HP. Advances in patient-derived tumor xenografts: from target identification to predicting clinical response rates in oncology. Biochem Pharmacol. 2014;91(2):135-43.

54. Malaney P, Nicosia SV, Dave V. One mouse, one patient paradigm: new avatars of personalized cancer therapy. Cancer Lett. 2014;344(1):1-12.

55. Konieczkowski DJ, Johannessen CM, Abudayyeh O, Kim JW, Cooper ZA, Piris $A$, et al. A melanoma cell state distinction influences sensitivity to MAPK pathway inhibitors. Cancer Discov. 2014;4(7):816-27.

56. Tirosh I, Izar B, Prakadan SM, Wadsworth MH 2nd, Treacy D, Trombetta JJ, et al. Dissecting the multicellular ecosystem of metastatic melanoma by single-cell RNA-seq. Science. 2016;352(6282):189-96.

\section{Publisher's Note}

Springer Nature remains neutral with regard to jurisdictional claims in published maps and institutional affiliations.

Ready to submit your research? Choose BMC and benefit from:

- fast, convenient online submission

- thorough peer review by experienced researchers in your field

- rapid publication on acceptance

- support for research data, including large and complex data types

- gold Open Access which fosters wider collaboration and increased citations

- maximum visibility for your research: over $100 \mathrm{M}$ website views per year

At $\mathrm{BMC}$, research is always in progress.

Learn more biomedcentral.com/submissions 